\title{
A Prospective Clinical Study of Maxillofacial Fractures and Their Management
}

\author{
Y. Suneel Kishore ${ }^{1}$, V. Sivarami Reddy ${ }^{2}$, B.R. N. Padmini ${ }^{3}$, K. Srinath ${ }^{4}$ \\ ${ }^{1}$ Assistant Professor, Department of General Surgery, Government Medical College and Hospital, Ongole, ${ }^{2}$ Retd Professor, \\ Department of Plastic Surgery, Osmania Medical College, Hyderabad, ${ }^{3}$ Assistant Professor, Department of General Surgery, \\ Siddhartha Medical College, Vijayawada, ${ }^{4}$ Assistant Professor, Department of Plastic Surgery, MNJ Cancer Institute, \\ Hyderabad, India
}

Corresponding author: K. Srinath, Part T, No.6, Vasavi Brindavanam, Fathenagar, Hyderabad 500018, India

DOI: http://dx.doi.org/10.21276/ijcmsr.2019.4.3.26

How to cite this article: Y. Suneel Kishore V. Sivarami Reddy, B.R. N. Padmini, K. Srinath. A prospective clinical study of maxillofacial fractures and their management. International Journal of Contemporary Medicine Surgery and Radiology. 2019;4(3):C114-C117.

\section{A B S T R A C T}

Introduction: The maxillofacial region of the face with its complexity is prone to injuries. The epidemiology and clinical presentation of these injuries can help in determining the prognosis and management and undertaking measures for prevention. The objective of this study was to assess the patterns of clinical presentation of maxillofacial fractures and associated injuries presenting to a tertiary care centre in Hyderabad and to determine the association between the fracture patterns and the mechanism of injury.

Material and methods: A prospective, clinical study of fractures of the maxillofacial region was carried out on 411 subjects from January 2011 to January 2013 in Osmania Medical College and Hospital, Hyderabad. The diagnosis was based on a detailed history and thorough clinical examination, confirmed by radiograph. Data were entered in Microsoft Excel and analysed with SPSS statistical software version 20.

Results: Major proportion (48\%) of the subjects were in the age group of 21 to 30 years. The majority (90\%) were males. RTA (Road traffic accidents) was the main risk factor (75\%) for maxillofacial fractures, followed by assaults (17\%) and falls (8\%). Mandible (47.9\%) was the most frequent location of the fracture. Isolated fractures of the mandible occurred in $45.74 \%$ of cases, and pan facial fractures occurred in $12.65 \%$.

Conclusions: Majority of the fractures affect the young men in their third decade of life. RTA continues to be the chief etiological factor in maxillofacial fractures. Mandible in the most common bone affected, followed by panfacial fractures.

Keywords: Maxillofacial Fracture, Injury, Trauma, Road Traffic Accidents (RTA), Mandible, Zygoma.

\section{INTRODUCTION}

The maxillofacial region of the face with its hard and soft tissues has very complex anatomy. ${ }^{1}$ In the human body, it is one of the most prone areas for fracture due to its prominent position. ${ }^{1,2}$ The mechanism of injury along with the direction of impact of the injury determines the location and pattern of such fractures. These injuries are frequently encountered in the practice of emergency medicine. ${ }^{3}$ They are also associated with high morbidity leading to increased costs of care and varying degrees of physical, functional and cosmetic disfigurement. Trauma to the face can result in lifethreatening complications as a result of airway obstruction or hemorrhage. Both soft and hard tissues of the face are involved in maxillofacial fractures from the frontal bone to the mandible. It may also be associated with fractures of other bones of the body. The common etiologies of maxillofacial fractures, across the world, are road traffic accidents, falls, assaults, firearm injury, sports and industrial accidents. A road traffic accident was reported to be the leading cause of maxillofacial fractures in developing countries. ${ }^{4,5}$ Accidents were also the most frequent cause in the age group of 18 to 39 years in developed countries, but in the age group of 40 to 59 years, it was interpersonal violence. ${ }^{6}$ The causes and pattern of maxillofacial injuries reflect trauma patterns within the community and have the potential for determining the objectives and design of national programmes and for determining the prognosis and day to day management and prevention, hence underlining the need of this study in a developing country like India. The objective of this study was to assess the patterns of clinical presentation of maxillofacial fractures and associated injuries presenting to a tertiary care centre in Hyderabad and to determine the association between the fracture patterns and the mechanism of injury.

\section{MATERIAL AND METHODS}

This was a prospective, clinical study of fractures of the maxillofacial region carried out on 411 patients, from January 2011 to January 2013 in Osmania Medical College and Hospital, Hyderabad. A detailed history with respect to sex, age, aetiology, nature and type of injury and fractures of the 
maxillofacial region clinically isolated and associated with panfacial fractures, their management and complications were analysed. Fractures of the Mandible, maxilla, zygomatic complex, nasal bones and pan facial fractures are included in this study, fractures of the orbit and frontal bones are excluded from this study. The diagnosis was based on a detailed history, and a thorough clinical examination, confirmed by radiographic investigations like digital x-rays, OPG, CT scan apart from routine investigations like CBP, blood grouping, chest X-ray.and also those patients with associated head, chest and abdominal injuries were referred as and when required. The surgical interventions used were a closed reduction (with arch bars, eye loops, and intermaxillary fixation) or open reduction and rigid internal fixation with mini plates, and screws, as appropriate. Complications studied included infection, malocclusion, nonunion, Malunion, paresthesias in the infraorbital nerve distribution, residual nasal deformity and implant removal. Data were presented by descriptive statistical analysis.

\section{RESULTS}

Among the study population, 8(2\%) were aged between 0 to 10 years, $70(17 \%)$ were aged between 11 to 20 years, 199(48\%) were aged between 21 to 30 years, 78(19\%) were aged 31 to 40 years, 35(9\%) were aged between 41 to 50 years and the remaining $21(5 \%)$ were aged more than 50 years. Among the study population, 369(90\%) participants were males and remaining $42(10 \%)$ participants were females. Among the study population, 308(75\%) were met with road traffic accidents, 70(17\%) were met assaults and remaining 33(8\%) were met with falls. (Table1)

Mandible (47.9\%) was the most frequent location of the fracture. Followed by nasal bones, zygoma, maxilla was $19.7 \%, 16.5 \%$ and $15.7 \%$ respectively. (Figure 1 )

Among the study population $188(45.74 \%)$ participants had fractured at isolated mandible, $28(6.81 \%)$ had fractured at maxilla, $72(17.51 \%)$ had fractured at the nasal bone, 48(11.67\%) had fractured at zygoma, 23(5.59\%) had fractured at combined maxilla, nasal bones and zygoma, $52(12.65 \%)$ had fractured at the pan facial site. Among the study population $280(68 \%)$ participants were done closed reduction type of surgical treatment and the remaining $131(32 \%)$ were done open reduction type of surgical

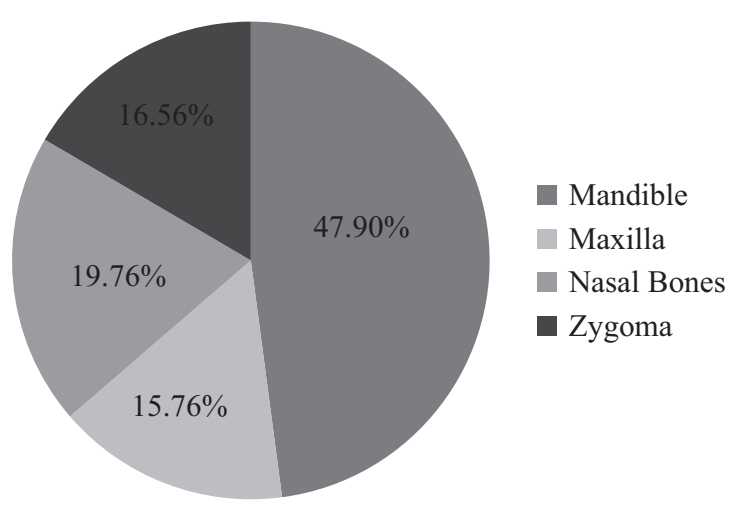

Figure-1: Frequency of involvement of various individual bony structures $(\mathrm{N}=501)$

\begin{tabular}{|c|c|c|}
\hline Parameter & No. of patients & Percentage \\
\hline \multicolumn{3}{|l|}{ Gender } \\
\hline Male & 369 & $90 \%$ \\
\hline Female & 42 & $10 \%$ \\
\hline \multicolumn{3}{|l|}{ Age in years } \\
\hline $0-10$ & 8 & $2 \%$ \\
\hline $11-20$ & 70 & $17 \%$ \\
\hline $21-30$ & 199 & $48 \%$ \\
\hline $31-40$ & 78 & $19 \%$ \\
\hline $41-50$ & 35 & $9 \%$ \\
\hline$>50$ Years & 21 & $5 \%$ \\
\hline \multicolumn{3}{|l|}{ Mode of injury } \\
\hline RTA (Road traffic accidents) & 308 & $75 \%$ \\
\hline Assaults & 70 & $17 \%$ \\
\hline Falls & 33 & $8 \%$ \\
\hline
\end{tabular}

\begin{tabular}{|l|c|c|}
\hline Anatomical site of Fracture (N=411) & 188 & $45.74 \%$ \\
\hline Isolated Mandible & 28 & $6.81 \%$ \\
\hline Isolated Maxilla & 72 & $17.51 \%$ \\
\hline Isolated Nasal Bone & 48 & $11.67 \%$ \\
\hline Isolated Zygoma & 23 & $5.59 \%$ \\
\hline Combined Maxilla, Nasal bones and Zygoma & 52 & $12.65 \%$ \\
\hline Pan Facial & 280 & $68 \%$ \\
\hline Type of surgical treatment performed (N=411) & 131 & $32 \%$ \\
\hline Closed reduction & Open reduction \\
\hline $\begin{array}{c}\text { Table-2: descriptive analysis of anatomical site of fracture and } \\
\text { surgical treatment performed (N=411) }\end{array}$ \\
\hline
\end{tabular}

treatment. (Table2)

\section{DISCUSSION}

Injuries of the Maxillofacial region are life-threatening and can have long-term residual effects. The epidemiology of these injuries is influenced by the mode and mechanism of injury besides several cultural, social and economic factors with wise country differences. There is a large variability in the epidemiology, etiology and clinical presentation of maxillofacial fractures due to a variety of social, environmental, cultural and economic factors. Osmania Medical College and Hospital, Hyderabad is a major trauma, and tertiary care centre in India and 411 subjects fulfilled the inclusion criteria from January 2011 to January 2013. The majority (48\%) of the subjects treated for maxillofacial fractures were in the age group of 21 to 30 years with male dominance (90\%). Similarly, Vujcich $\mathrm{N}$ et $\mathrm{al}^{1}$ in their major tertiary trauma hospital in Western Australia observed that the mean average age of subjects with facial fractures was 28 years with the majority being males (87\%) similar to our study. Kamath $\mathrm{RA}$ et $\mathrm{al}^{7}$ also observed that subjects between the age of 21 to 30 years were more commonly affected, attributing to $43.2 \%$ of the study population. Similar to our study, they also observed that the majority (90.5\%) of the subjects were males. This higher incidence in men between the age of 21 to 30 years could be due to the risk-taking behaviour of young 
adult males and to the confinement of women to their homes resulting in their reduced exposure to road traffic accidents, sports and interpersonal violence compared to males. People in the age group of 21 to 30 years have adventurous behaviour, and also they lack the experience which comes with subjects of older age and tend to disregard traffic rules. In this study, RTA (Road traffic accidents) was the main risk factor (75\%) for maxillofacial fractures, followed by Assaults (17\%) and falls (8\%). The increase in the number of RTA in developing countries like India can be due to various factors like low standards of driving and sharing of roadways between fast-moving and slow-moving vehicles with pedestrians. Other studies have also reported RTA as a major cause of maxillofacial fractures in developing countries ${ }^{4,5}$ while accidents in young age and interpersonal violence in the older people were reported as the frequent cause in developed countries. ${ }^{6,8}$ The number of maxillofacial fractures in children is also on the rise. ${ }^{9,10}$ Elarabi MS et al ${ }^{11}$ in their study also observed that RTA (58\%) was the most frequent cause of maxillofacial fracture followed by assault (17\%) in western libya. In Amsterdam it was observed that the most common cause of the maxillofacial fracture was traffic related, followed by violence. ${ }^{12}$ Bali $\mathrm{R}$ et $\mathrm{al}^{5}$ in their study in Haryana also observed that RTA was the major etiological factor (71.89\%) followed by falls (16.2\%) and assault (5.6\%). In their study, the major proportion of RTA occurred with 2 - wheelers (490 out of 532). In a study reported from Karnataka, the majority of the fractures of the maxillofacial region occurred due to RTA $(74.7 \%)$ followed by interpersonal violence (15.8\%) and falls (4.2\%). In the human face, the upper third includes the frontal bone; the mid-third includes the maxilla, zygomas, orbits, nose and naso-orbital ethmoidal complex while the lower third comprises of the mandible. Mandible (47.9\%) was the most frequent location of the fracture in this study, followed by Nasal bones (19.76\%), Zygoma (16.56\%) and Maxilla (15.76\%). In our study, isolated fractures of the mandible occurred in $45.74 \%$ of cases, and pan facial fractures occurred in $12.65 \%$. This is similar to a study done by $\mathrm{Natu} \mathrm{SS}$ et $\mathrm{al}^{13}$ (isolated mandible fractures in $62.2 \%$ and associated fractures in $37.88 \%)$. With regards to fracture patterns in this study, isolated mandible fracture (45.74\%) was the most common type followed by Isolated nasal bone fractures (17.51\%). Similar to our study, Elarabi MS et $\mathrm{al}^{11}$ also reported that mandible (58\%) was the most commonly involved site of fracture in their study. Van den Bergh B et $\mathrm{al}^{12}$, in their study, also reported that mandibular and zygomatic bone fractures were the most frequent. Similar to our study, Fractures of the mandible were the most frequent (66.9\%) followed by fractures of the middle third in a study reported by Bali $\mathrm{R}$ et al. ${ }^{5}$ Mandible bone is one of the most frequent bone-targeted in fights, because the mandible is anterior and mobile bone it is commonly fractured in RTAs. $44.2 \%$ of subjects had isolated Zygomaticomaxillary complex fractures in the study on maxillofacial trauma as reported by Kamath RA et al. ${ }^{7}$ In the past few decades, major advances have occurred in the field of management of maxillofacial fractures with the change from closed to open reduction and internal fixation. Plate and screw fixation has also developed over the years. The common type of surgical treatment done in this study was a closed reduction (68\%) while the open reduction was only done in $32 \%$ of subjects. This is due to minimum facilities in government hospitals and associated with high turnover of patients. Elarabi MS et $\mathrm{al}^{11}$, in their study, reported that open reduction and fixation with plates and other alloplastic materials (71\%) was the mainstay of treatment. Bali $\mathrm{R}$ et $\mathrm{al}^{5}$ in their study also reported Open reduction $(62.6 \%)$ was the mainstay of treatment followed by closed reduction (36.8\%) for fractures of the mandible. For fractures of middle third, closed reduction (48.4\%) was the most frequent in their study. $92 \%$ of maxillofacial fractures were treated with open reduction and internal fixation (ORIF) in the study by Kamath RA et al. ${ }^{7}$

Our study was limited by its smaller sample size and the study sample, which included only the hospital subjects. A community-based study would have given better statistical estimates.

\section{CONCLUSION}

It can be concluded from the results of our study that the high frequency of maxillofacial fractures due to RTA in our population. Unlike in developed countries where assaults are the most frequent cause of maxillofacial fractures, RTA continues to dominate in India. It highlights the need for the strict enforcement of traffic rules and regulations. Given the preventable morbidity and mortality due to inadequate treatment, the establishment of regionalised, efficient, and focused trauma centres in various parts of the state, particularly for acute trauma is the need of the hour.

\section{REFERENCES}

1. Vujcich N, Gebauer D. Current and evolving trends in the management of facial fractures. Aust Dent J. 2018;63 Suppl 1:S35-47.

2. Gassner R, Tuli T, Hachl O, Rudisch A, Ulmer H. Cranio-maxillofacial trauma: a 10 year review of 9,543 cases with 21,067 injuries. J Craniomaxillofac Surg. 2003;31(1):51-61.

3. DeAngelis AF, Barrowman RA, Harrod R, Nastri AL. Review article: Maxillofacial emergencies: Maxillofacial trauma. Emerg Med Australas. 2014;26(6):530-7.

4. Mijiti A, Ling W, Tuerdi M, Maimaiti A, Tuerxun J, Tao YZ, et al. Epidemiological analysis of maxillofacial fractures treated at a university hospital, Xinjiang, China: A 5-year retrospective study. J Craniomaxillofac Surg. 2014;42(3):227-33.

5. Bali R, Sharma P, Garg A, Dhillon G. A comprehensive study on maxillofacial trauma conducted in Yamunanagar, India. J Inj Violence Res. 2013;5(2):10816.

6. Arangio P, Vellone V, Torre U, Calafati V, Capriotti M, Cascone P. Maxillofacial fractures in the province of Latina, Lazio, Italy: review of 400 injuries and 83 cases. J Craniomaxillofac Surg. 2014;42(5):583-7.

7. Kamath RA,Bharani S,Hammannavar R, Ingle SP, Shah AG. Maxillofacial trauma in central karnataka, India: an outcome of 95 cases in a regional trauma care centre. Craniomaxillofac Trauma Reconstr. 2012;5(4):197-204.

8. Boffano P, Roccia F, Zavattero E, Dediol E, Uglesic $\mathrm{V}$, Kovacic Z, et al. European Maxillofacial Trauma 
(EURMAT) project: a multicentre and prospective study. J Craniomaxillofac Surg. 2015;43(1):62-70.

9. Singhal R, Singh V, Bhagol A, Agrawal A, Kumar P. Pediatric maxillofacial injuries - if a new look is required? Int J Pediatr Otorhinolaryngol. 2013;77(8):1333-6.

10. U1 Haq ME, Khan AS. A retrospective study of causes, management, and complications of pediatric facial fractures. Eur J dent. 2018;12(2):247-52.

11. Elarabi MS, Bataineh AB. Changing pattern and etiology of maxillofacial fractures during the civil uprising in Western Libya. Med Oral Patol Oral Cir Bucal. 2018;23(2):e248-55.

12. van den Bergh B, Karagozoglu KH, Heymans MW, Forouzanfar T. Aetiology and incidence of maxillofacial trauma in Amsterdam: a retrospective analysis of 579 patients. J Craniomaxillofac Surg. 2012;40(6):e165-9.

13. Natu SS, Pradhan H, Gupta H, Alam S, Gupta S, Pradhan $\mathrm{R}$, et al. An epidemiological study on pattern and incidence of mandibular fractures. Plast Surg Int. 2012;2012:834364.

Source of Support: Nil; Conflict of Interest: None

Submitted: 15-06-2019; Accepted: 10-07-2019; Published online: 28-08-2019 